\title{
Osteolytic Lumbar Discal Cyst
}

\author{
-Case Report-
}

\author{
Aiki MARUSHIMA, Kazuya UEMURA*, Naoaki SATO, \\ Toru MARUNO, and Akira MATSUMURA* \\ Department of Neurosurgery, Kobari General Hospital, Noda, Chiba; \\ ${ }^{*}$ Department of Neurosurgery, Institute of Clinical Medicine, \\ University of Tsukuba, Tsukuba, Ibaraki
}

\begin{abstract}
A 25-year-old man presented with left lumboischialgia refractory to medical treatment. Neurological examination revealed $L 5$ and $S 1$ radiculopathy which rapidly worsened over a short period. Magnetic resonance imaging demonstrated disk bulging with a discal cyst at the L4-5 intervertebral space and disk herniation at the L5-S1 intervertebral space. Computed tomography showed osteolytic change of the $L 5$ vertebral body adjacent to the cyst. Resection of the cyst and removal of the herniated disk were performed following fenestration of the L4-5 and L5-S1 interlaminar spaces. Bloody serous fluid followed by clear serous fluid was recognized during the aspiration and partial resection of the cyst at the L4-5 level. Histological examination demonstrated a cyst wall consisting of fibrous connective tissue without a single-layer lining of cells, and fibrin deposits. The patient's symptoms disappeared immediately after the operation. This osteolytic lumbar discal cyst possibly occurred subsequent to hemorrhage from the epidural venous plexus following intervertebral disk injury, hematoma encapsulation by connective fibrous tissue, and cyst wall formation in reaction to the disk injury and hemorrhage. The cyst may have enlarged due to the inflow of the serous fluid from the water-containing degenerated disk.
\end{abstract}

Key words: lumbar discal cyst, osteolysis, radiculopathy, check-valve mechanism

\section{Introduction}

Lumbar discal cyst is a spinal epidural cyst consisting of connective fibrous tissue containing bloody to clear serous discharge, usually associated with degeneration of the corresponding intervertebral disk. ${ }^{5,9)}$ The discal cyst may compress the nerve root resulting in radiculopathy. The symptoms can be treated by resecting the cyst. ${ }^{4-7,9,10,15,21-23)}$ Careful diagnosis is needed to differentiate discal cysts from other extradural cysts such as synovial cysts, ${ }^{17,24)}$ ganglion cysts, ${ }^{3,8,11,16)}$ gas-containing cysts, ${ }^{11,18)}$ perineural cysts, ${ }^{20)}$ and extradural arachnoid cysts. ${ }^{12,13)}$ The pathogenesis of discal cysts remains unclear. Discal cyst was first described in Japan in $1995,4,5,22,23)$ and 21 cases of discal cysts have been described. ${ }^{4-7,9,10,21)}$
Here, we report a case of lumbar discal cyst associated with osteolytic change of the lumbar vertebra causing radiculopathy which worsened with enlargement of the discal cyst, but improved immediately following surgical resection.

\section{Case Report}

A 25-year-old man came to our hospital complaining of lower back and left leg pain persisting for 3 months. Neurological examination revealed left radicular pain, and disturbed pinprick, light, and deep touch sensation in the left L5 and S1 dermatomes. Lasègue's sign was positive for the left leg. No muscle weakness was indicated. Achilles tendon reflex was within the normal range. Magnetic resonance (MR) imaging demonstrated disk bulging

Received April 19, 2007; Accepted May 7, 2008

Authors' present addresses: Aiki Marushima, M.D., Department of Neurosurgery, Institute of Clinical Medicine, University of Tsukuba, Tsukuba, Ibaraki, Japan; Kazuya Uemura, M.D., Department of Neurosurgery, Kennan Hospital, Tsuchiura, Ibaraki, Japan; Toru Maruno, M.D., Department of Neurosurgery, Maruno Clinic, Toride, Ibaraki, Japan. 

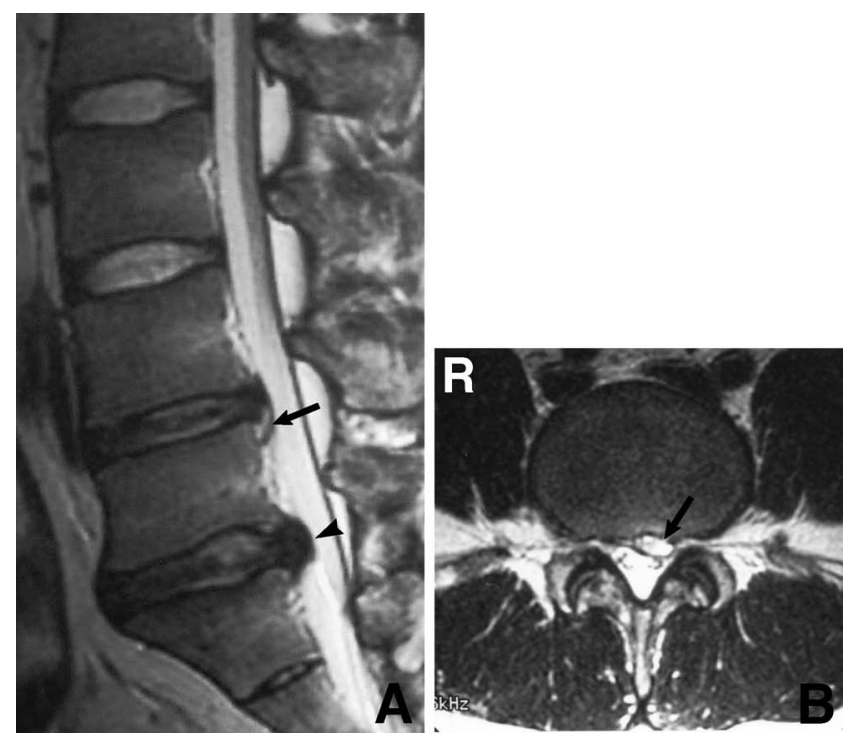

Fig. 1 Sagittal (A) and axial (B) $\mathrm{T}_{2}$-weighted magnetic resonance images demonstrating disk bulging with a small cystic component (arrow) at the L4-5 intervertebral space, and disk herniation (arrowhead) at the L5-S1 intervertebral space.

with a small cystic lesion at the L4-5 intervertebral space, and disk herniation at the L5-S1 intervertebral space, causing compression of the left L5 and S1 nerve roots, respectively (Fig. 1).

The patient was given analgesics and muscle relaxants. Epidural injection of local anesthetic and steroid was performed for the radiculopathy of the left L5 and S1 nerve roots. However, his symptoms progressed under conservative treatment. The patient developed difficulty in walking due to severe lower back and left leg pain. Repeated MR imaging of the lumbar vertebra 6 months later demonstrated enlargement of the cystic component at the L4-5 level (Fig. 2). Computed tomography (CT) following myelography showed osteolytic change of the L5 vertebral body surrounding the cystic component (Fig. 3).

Surgical treatment was performed for the enlarged cyst at the L4-5 level and the herniated disk at the L5-S1 level because both lesions were related to the deterioration of the patient's symptoms. After fenestration of the left L4-5 and L5-S1, the thecal sac and S1 nerve root were decompressed following adequate removal of the herniated disk at the L5-S1 level. A dark blue cyst compressing the left L5 nerve root was exposed on the caudal side at the L4-5 level. Bloody serous fluid followed by clear serous fluid was aspirated from the dissected cyst. The L5 nerve root was adequately decompressed after the cyst had
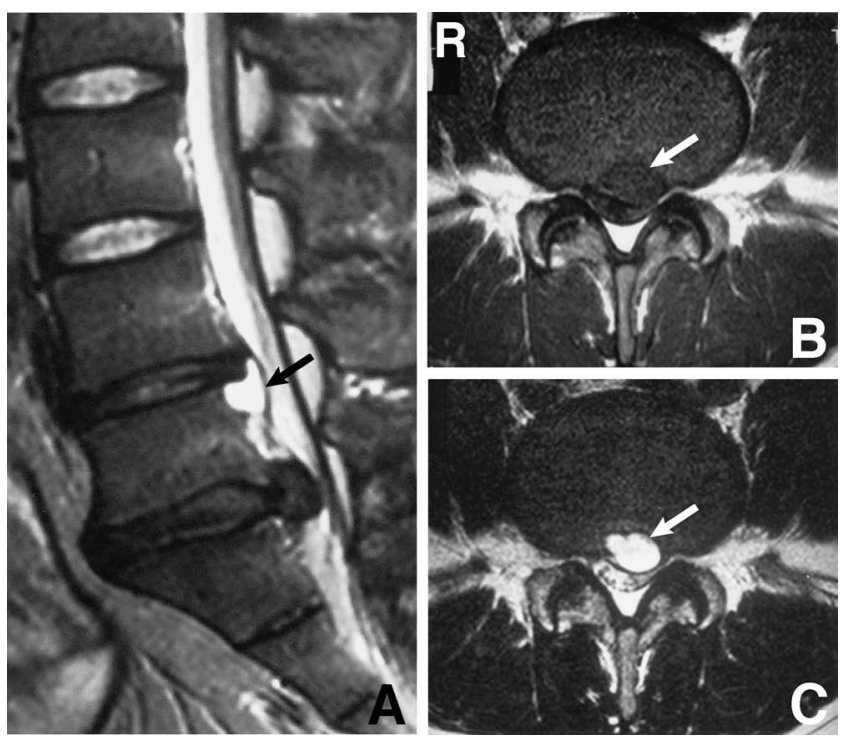

Fig. 2 Sagittal $T_{2}$-weighted magnetic resonance (MR) image (A) performed 6 months later demonstrating enlargement of the cystic component (arrow) at the L4-5 level. Axial $T_{1^{-}}$(B) and $T_{2}$-weighted (C) $M R$ images at the L4-5 level demonstrating a discal cyst compressing the L5 nerve root dorsally, with an intracystic component appearing as hypointense and hyperintense, respectively (arrow).
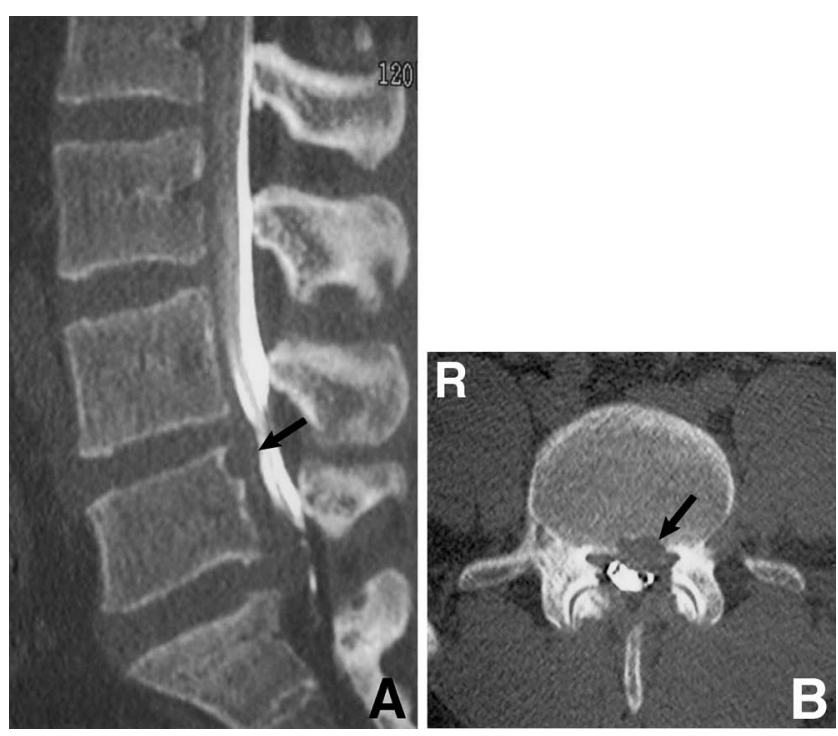

Fig. 3 Sagittal computed tomography (CT) scan (A) and axial CT scan at the L4-5 level (B) demonstrating osteolytic change of the L5 vertebral body adjacent to the discal cyst (arrow). 


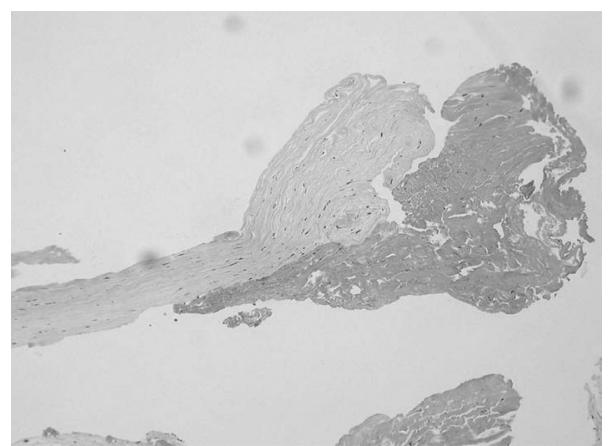

Fig. 4 Photomicrograph demonstrating the cyst wall consisting of fibrous connective tissue without a single-layer lining of cells, and fibrin deposits. Hematoxylin and eosin stain, original manifestation $\times 100$.

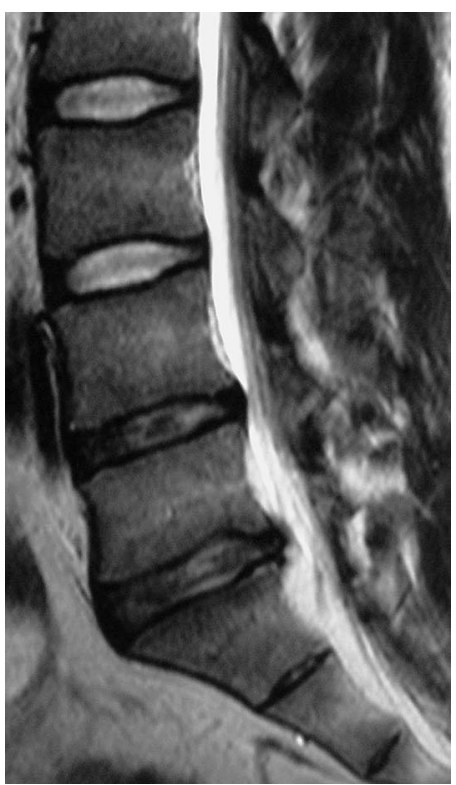

Fig. 5 Sagittal $\mathbf{T}_{2}$-weighted magnetic resonance image after the operation demonstrated shrinkage of the discal cyst at the L4-5 level and disappearance of the herniated disk at the L5-S1 level.

shrunk. A gaping hole was seen in the posterior aspect of the L5 vertebral body following the aspiration and partial resection of the cyst. Histological examination demonstrated the cyst wall consisted of fibrous connective tissue without a single-layer lining of cells, and fibrin deposits (Fig. 4).

Immediately after the operation, the L5 and S1 radiculopathy disappeared (Fig. 5). The patient's Japanese Orthopaedic Association score was improved from $10 / 29$ preoperatively to $29 / 29$ postoperatively. He was discharged without requiring analgesic drugs.

\section{Discussion}

Previous cases of discal cyst occurred in 18 men and 3 women aged 13-69 years at the time of surgery (mean 31.7 years), which is younger than that of intervertebral disk herniation. Including the present case, the affected intervertebral level was L1-2 in one case, L2-3 in four cases, L3-4 in five cases, L4-5 in twelve cases, and L5-S1 in one case.

Changes in the vertebral body associated with the discal cyst occurred in three cases, ${ }^{9,10)}$ and all showed bony erosion of the adjacent lateral recess, which is thought to be a less resistant part of the intraspinal epidural space. ${ }^{2,19)} \mathrm{CT}$ and MR imaging demonstrated eroded bone cortex adjacent to the cyst but no erosion extending to the bone marrow of the vertebral body. In our case, the cyst had also completely eroded the bone cortex, and osteolysis extending to the bone marrow had occurred over 6 months.

Several types of pathogenesis for discal cysts have been proposed. One hypothesis is that the discal cyst develops as a result of specific impairment in the absorption of epidural hematoma. ${ }^{23)}$ Another idea is that underlying intervertebral disk injury occurred initially as the basis for the development of a discal cyst, and hemorrhage from the epidural venous plexus was initiated by mechanical force associated with disk injury, and the hematoma was encapsulated during absorption by the membrane such as mucous-degenerated tissue at the surface of the hematoma. ${ }^{5}$ Another theory is the formation of a reactive pseudomembrane following intervertebral disk degeneration with subsequent fluid collection from the degenerated disk material, so the cyst becomes enlarged as a result of accumulation of the fluid in the pseudomembrane. ${ }^{9)}$

In the present case, we suggest that hemorrhage occurred from the epidural venous plexus following intervertebral disk injury, the hematoma was encapsulated by connective fibrous tissue, and the cyst wall was created in reaction to the disk injury and hemorrhage, similarly to the formation of a meniscal cyst in the knee. ${ }^{1)}$ The presence of fibrin inside the cyst wall indicated that old hematoma had coagulated and dissolved. The discal cyst usually communicates with its associated degenerated disk, as described in previous cases. ${ }^{4-7,9,10,15,21-23)}$ Furthermore, the cyst wall is exposed to the increased pressure in the degenerated disk caused by the mechanical stress on the lumbar vertebral body.

The cyst in our patient may have been enlarged by the inflow of the serous fluid from the water-containing degenerated disk. The mean age in patients with discal cysts is younger than that of patients 
with intervertebral disk prolapse, suggesting that a water-containing degenerated disk with sufficient fluid is a prerequirement to accumulate the serous fluid in a discal cyst. The presence of bone erosion around the cyst in our patient implies that the intracystic pressure had remained high, which may indicate that the check-valve mechanism was involved in the enlargement of the cyst. The check-valve mechanism is important in maintaining a higher pressure in the cyst than in the circumference outside of the cyst. ${ }^{12-14)}$ Therefore, the serous fluid from the degenerated disk flowed into the cyst through the check-valve created by the degenerative disk material and the cyst wall, but could not be discharged from the cyst. Therefore, the discal cyst containing bloody and clear serous fluid enlarged within a short period, and the continuous high pressure in the cyst caused erosion of the vertebral body.

Clinicians must carefully monitor changes in neurological findings, because a discal cyst may enlarge within a short period, as in this case. Surgical resection may be effective for reducing the symptoms in a patient with radiculopathy caused by discal cyst enlargement.

\section{References}

1) Barrie HJ: The pathogenesis and significance of menisceal cysts. J Bone Joint Surg Br 61-B: 184-189, 1979

2) Bartynski WS, Lin L: Lumbar root compression in the lateral recess: $\mathrm{MR}$ imaging, conventional myelography, and CT myelography comparison with surgical confirmation. AJNR Am J Neuroradiol 24: 348-360, 2003

3) Brish A, Payan HM: Lumbar intraspinal extradural ganglion cyst. J Neurol Neurosurg Psychiatry 35: 771-775, 1972

4) Chatani K, Kamata Y, Shirokura M, Watanabe N, Ogura S, Hase H, Hirasawa Y: [Intraspinal cystic hematoma associated with lumbar disc herniation]. Nippon Seikei Geka Gakkai Zasshi 70: S316, 1996 (Jpn)

5) Chiba K, Toyama Y, Matsumoto M, Maruiwa $H$, Watanabe $M$, Nishizawa T: Intraspinal cyst communicating with the intervertebral disc in the lumbar spine: discal cyst. Spine 26: 2112-2118, 2001

6) Coscia MF, Broshears JR: Lumbar spine intracanalicular discal cysts: two case reports. J Spinal Disord Tech 15: 431-435, 2002

7) Jeong GK, Bendo JA: Lumbar intervertebral disc cyst as a cause of radiculopathy. Spine J 3: 242-246, 2003

8) Kao CC, Uihlein A, Bickel WH, Soule EH: Lumbar intraspinal extradural ganglion cyst. J Neurosurg 29: 168-172, 1968

9) Kono K, Nakamura H, Inoue Y, Okamura T, Shakudo M, Yamada R: Intraspinal extradural cysts communicating with adjacent herniated disks: imaging characteristics and possible pathogenesis. AJNR Am J Neuroradiol 20: 1373-1377, 1999

10) Lee HK, Lee DH, Choi CG, Kim SJ, Suh DC, Kahng SK, Roh SW, Rhim SC: Discal cyst of the lumbar spine: MR imaging features. Clin Imaging 30: 326330, 2006

11) Lin RM, Wey KL, Tzeng CC: Gas-containing “ganglion" cyst of lumbar posterior longitudinal ligament at L3. Case report. Spine 18: 2528-2532, 1993

12) Liu JK, Cole CD, Sherr GT, Kestle JRW, Walker ML: Noncommunicating spinal extradural arachnoid cyst causing spinal cord compression in a child. J Neurosurg 103(3 Suppl): 266-269, 2005

13) McCrum C, Williams B: Spinal extradural arachnoid pouches. Report of two cases. J Neurosurg 57: 849852, 1982

14) Nabors MW, Pait TG, Byrd EB, Karim NO, Davis DO, Kobrine AI, Rizzoli HV: Updated assessment and current classification of spinal meningeal cysts. J Neurosurg 68: 366-367, 1988

15) Nishizawa T, Koyanagi T, Toyama $Y$, Fujimura S, Ishinada Y, Izumida R, Kimijima Y: [Three cases of intraspinal cyst whose symptoms resembled lumbar disc herniation]. Seikei Geka 46: 1353-1356, 1995 (Jpn)

16) Ogawa Y, Kumano K, Hirabayashi S, Aota Y: A ganglion cyst in the lumbar spinal canal. A case report. Spine 17: 1429-1431, 1992

17) Onofrio BM, Mih AD: Synovial cysts of the spine. Neurosurgery 22: 642-647, 1988

18) Pierpaolo L, Luciano M, Fabrizio P, Paolo M: Gascontaining lumbar disc herniation. A case report and review of the literature. Spine 18: 2533-2536, 1993

19) Schneck CD: The anatomy of lumbar spondylosis. Clin Orthop Relat Res 193: 20-37, 1985

20) Tarlov IM: Perineural cysts of the nerve root. Arch Neurol 40: 1067-1074, 1938

21) Tokunaga M, Aizawa T, Hyodo H, Sasaki H, Tanaka Y, Sato T: Lumbar discal cyst followed by intervertebral disc herniation: MRI findings of two cases. J Orthop Sci 11: 81-84, 2006

22) Tokutani S, Katano H, Ichikawa S, Ishibashi K, Echigoya N, Miura K, Yokoyama T, Tomita S: [Intraspinal cyst (premembranous hematoma): a case report]. Rinsho Seikei Geka 31: 1195-1198, 1996 (Jpn)

23) Toyama Y, Kamata M, Matsumoto M, Nishizawa T, Koyanagi T, Suzuki N: [Pathogenesis and diagnostic title of intraspinal cyst communicating with intervertebral disc in the lumbar spine]. Rinsho Seikei Geka 32: 393-400, 1997 (Jpn)

24) Yuh WT, Drew JM, Weinstein JN, McGuire CW, Moore TE, Kathol MH, el-Khoury G: Intraspinal synovial cysts. Magnetic resonance evaluation. Spine 16: 740-745, 1991

Address reprint requests to: Aiki Marushima, M.D., Department of Neurosurgery, Institute of Clinical Medicine, University of Tsukuba, 1-1-1 Tennodai, Tsukuba, Ibaraki 305-8575, Japan. 